\title{
Políticas linguísticas e historicização do Brasil: a escrita na construção vernacular
}

Anderson Salvaterra Magalhães (UFSM/FAPERGS)

\section{Resumo}

Tradicionalmente a história do Brasil se conta do ponto de vista europeu colonizador, mais especificamente, da perspectiva do português, e a questão linguística desempenha importante função no modo como a brasilidade pôde e pode ser significada. Neste artigo, o objetivo é demonstrar como a escrita instaura uma arena de sentidos determinante para os discursos constitutivos do senso de vernáculo no e do Brasil. Para isso, foram selecionados dois documentos flagrantes da tensão estabelecida pela política linguística da Coroa Portuguesa: a) a Carta Régia declarando guerra contra os indios chamados botocudos e b) um texto editorial publicado no Correio Braziliense sobre tal Carta. A análise desses documentos destaca dois pontos fundamentais para a possibilidade de construção vernacular: 1) a política linguística portuguesa impôs uma ordem letrada e o saber por ela e nela referendado em detrimento da ordem regida pela oralidade e o saber por ela e nela valorado; 2) a escrita corroborava simultaneamente o valor e a reacentuação do valor da língua portuguesa no funcionamento cultural que se instituía, sendo instrumento de afirmação e questionamento de ideologias linguísticas. Assim, a escrita no Brasil mobilizou campos discursivos reguladores da relação entre língua e sociedade decisiva para a historicização do país.

Palavras-chave: políticas linguísticas; língua portuguesa; vernáculo; escrita. 


\section{Introdução}

A história do Brasil é tradicionalmente contada do ponto de vista do português. A chegada dos lusitanos em 1500 tem sido referida como "descobrimento do Brasil", ou, "achamento do Brasil", como já registrara Pero Vaz de Caminha em sua Carta ao Rei, uma das primeiras narrativas a significar este espaço da perspectiva a ser consolidada nos discursos da história do Brasil. A designação descobrimento do Brasil guarda um tom inaugural, como se tudo começasse ali, e ratifica o ponto de vista do qual se conta essa história. Daí, duas questões podem ser levantadas: 1) como é possível falar em descobrimento ou achamento de um território habitado, com sociedades organizadas, ainda que organizadas de um modo diferente daquele dos supostos descobridores? 2) o que significa nomear "descobrimento do Brasil" ou "achamento do Brasil" a chegada dos portugueses num território que não se identificava ou se definia como Brasil? Por um lado, a ideia de descobrimento evidencia que o que se passou nesse lugar antes do projeto comercial e colonizador português não é alcançado pelo foco lançado desse ponto de vista e, por isso, não integra a dinâmica dessa história. Por vezes, o que antecede à presença lusitana no Brasil aparece como cenário, mas nunca como força dramática, por assim dizer. Por outro lado, a designação Brasil não condiz com o nome dado às terras conhecidas pelos portugueses por ocasião do "achamento", mas recolhe em uma palavra um conjunto de designações que remontam às nuanças da organização política deste espaço a partir da colonização: Terra de Vera Cruz, Terra de Santa Cruz, Brasil (Colônia), Império do Brasil, Estados Unidos do Brasil, República Federativa do Brasil. Mais do que escolha lexical, falar em "descobrimento do Brasil" implica falar dos sentidos que atravessam fatos históricos determinantes do que o Brasil é hoje; sentidos mobilizados de um lugar social que permite significar tais fatos de uma maneira, e não de outra, e a língua portuguesa tem uma função preponderante nesse processo de historicização.

A chegada dos portugueses ao que hoje se chama Brasil dá início a um processo de transformação da ordem social local. Instaura-se um embate entre o paradigma organizacional europeu e aquele praticado pelos povos indígenas que aqui habitavam. Gradativamente os valores sociopolíticos indígenas vão perdendo relevância simbólica para o funcionamento europeu, que se impunha como padrão. Organização política, língua de comunicação, religião, relações familiares etc.; muitos eram os pontos de conflito de valores. A Carta de Pero Vaz de Caminha documenta, em língua portuguesa, os primeiros contatos entre lusitanos e indígenas e fundamenta um modo de fazer sentido do Brasil no qual o índio não é população autóctone, mas o outro, o exótico, de conhecimento lacunar. Falta roupa, falta vergonha, falta temor à religião cristã e, portanto, do ponto de vista europeu, falta 
conhecimento de Deus, falta rei, falta escrita, entre tantas outras ausências. A Carta de Pero Vaz registra um ponto de vista que passa a regular as relações de identidade/alteridade aqui entretecidas e que encaminha possibilidades vernaculares. Aquilo que é definido como próprio desta terra é mediado por esse olhar, e o fato de uma carta funcionar como registro válido de memória dessa historicização evidencia o sucesso do empreendimento português. Nesse processo de documentação, a escrita suplanta a oralidade, e a língua portuguesa, as diversas línguas indígenas.

A consolidação da língua lusitana no Brasil, porém, não foi garantido pela Carta, nem pelas primeiras ações de Portugal sobre este espaço. Até o século XVIII, competiam com o português, que se difundia sobretudo na costa brasileira, duas línguas francas - a língua geral paulista e a amazônica (NOLL, 2010) - difundidas principalmente no interior a partir do contato entre indígenas e bandeirantes. As línguas gerais também compunham o projeto jesuítico de catequese, que advogava a necessidade de significar a "religião do Rei" na língua local (MARIANI, 2004). Sendo assim, a coletividade brasileira que se costurava no período colonial definia-se em meio ao contato de diversas línguas indígenas, duas versões de língua geral - a paulista e a amazônica - e o português, que chegava ao Brasil na boca de lusitanos das mais variadas regiões de Portugal e de diferentes posições sociais (NARO; SCHERRE, 2007; DEL PRIORE; VENANCIO, 2010; NOLL, 2010). No decorrer do processo de colonização, por conta do desajuste entre o empreendimento da Igreja Católica e o da Coroa Portuguesa, D. José I, rei de Portugal, edita em 1757, por meio do seu ministro, o Marquês de Pombal, o Diretório dos Índios que, entre outras providências, instituía a língua portuguesa como único idioma válido na então Colônia. É a partir daí que a língua portuguesa começa a ocupar função preponderante não apenas na comunicação no Brasil, mas também no processo de significá-lo aqui (MARIANI, 2004).

Nesse cenário que se recupera entre os séculos XVI eXIX, importante instrumento para o fortalecimento da língua portuguesa na historicização do Brasil são a escrita e os campos discursivos por meio dela mobilizados. No período focado, dois desses campos merecem destaque: o da jurisprudência e o do jornalismo. $\mathrm{O}$ primeiro promove a redefinição das relações sociais culturalmente validadas, uma vez que o funcionamento sociopolítico europeu, regido pela legislação escrita, se impõe à cultura oral indígena. O segundo configura uma arena de sentidos também mediada pela escrita, um lugar de embate entre discursos, um lugar de afirmação e questionamento de valores.

Com o objetivo de demonstrar como esses dois campos instauram tensão de sentidos determinante para o senso de vernáculo no e do Brasil, são analisados, neste artigo, dois documentos em língua portuguesa: uma Carta Régia de 13 de maio de 1808 que 
manda fazer guerra aos índios Botocudos (BRASIL, 1808) e um texto jornalístico, de caráter editorial, sobre tal carta publicado na edição de outubro de 1808 do Correio Braziliense (BRAZIL, 1808). A carta constitui flagrante da imposição da ordem letrada europeia na Colônia, e o texto editorial, simultaneamente subscreve essa imposição e, simultaneamente, resiste a ela. Ambos, discurso e contradiscurso, consolidam uma política a favor da língua portuguesa na Colônia, mas orientam de maneira diferente a construção vernacular no Brasil.

Para alcançar esse objetivo, a presente discussão desenvolve-se em três principais eixos. No primeiro, reflete-se acerca da relação entre política linguística e historicização, pontuando como a questão da língua, especialmente por meio da escrita, deflagrou um modo de significar a organização social, política e cultural do que viria a ser o Brasil. No segundo, destacam-se aspectos extrínsecos e intrínsecos à língua portuguesa determinantes para sua consolidação como possibilidade vernacular, bem como a função da escrita como poderoso equipamento para ordem social que se impunha. No terceiro eixo, analisam-se os documentos para demonstrar como a escrita e os valores com ela mobilizados funcionaram na consolidação de uma política reguladora de possibilidade vernacular no Brasil.

\section{Política linguística e historicização: a questão da escrita}

A situação linguística do Brasil Colônia se definia pela multiplicidade de línguas em contato. Na chamada era pré-cabralina, as diversas tribos que habitavam estas terras já vivenciavam variadas fronteiras linguísticas ao longo do território que viria a constituir o Brasil, e a chegada dos europeus, em particular, a dos portugueses torna o quadro ainda mais complexo. Para compreender o redimensionamento da situação linguística e seus desdobramentos políticos, é preciso entender o conflito de valores deflagrado a partir do choque entre o funcionamento cultural europeu e o dos indígenas.

Chamie (2002) identifica o enfrentamento da cultura oral indígena com a letrada europeia como o principal embate estabelecido aqui em 1500. De acordo com o autor, o texto da Carta de Pero Vaz de Caminha deixa evidências de um estranhamento que pode ser metonimicamente recuperado pela tensão entre uma tradição oral e uma cultura escrita. Entender a metonímia, porém, demanda o reconhecimento de funcionamentos culturais que se projetam simbolicamente na escrita e em sua ausência.

Desde a Grécia Antiga, berço da cultura ocidental, há referenciais que integram os diferentes modos como a ordem social tem sido significada. Integram, não determinam. Isso porque a cultura não constitui entidade estanque, mas processo dinâmi$\mathrm{co}$, negociado e renegociado pelas relações sociais que costuram coletividades, e o funcionamento cultural está fundamentado 
em valores que servem como parâmetro para essas relações. Os valores também são dinâmicos e negociados, de maneira que a estabilização cultural não se traduz pela fixidez, e sim pela preponderância de determinado valor como regulador da ordem social.

Segundo Amorim (2007), na história da cultura ocidental há três grandes eixos de valor, cada um dos quais marcado pelo predomínio de um modo de relação entre o saber e o discurso estruturado partir de um determinado princípio que regula o referencial axiológico. Desses eixos, destacam-se dois pertinentes à questão da política linguística empreendida pela colonização portuguesa.

No eixo que a autora denomina Mythos, o princípio da "verdade como memória" regula o funcionamento da cultura. Esta seria a base das sociedades tradicionais, por vezes, ágrafas. Em oposição ao esquecimento, a verdade é validada pelo mito, por aquilo que se transmite por gerações, pelas profecias ou por oráculos. A verdade não se vincula à novidade, mas ao repetido, mantido e estabilizado por meio do saber mítico, organizado na forma narrativa. Nesse universo de sentido, a forma de saber ordena-se na esfera da expressão e tem a memória como seu critério de validação. Não esquecer é condição para ser. Rituais, cerimônias, instituições que se estruturam a partir daí sustentam-se como manifestações entre sujeitos, e o objetivo das relações é o estabelecimento do laço social.

O funcionamento Mythos não necessariamente dispensa a escrita, mas convoca a oralidade para manutenção dessas relações intersubjetivas que simultaneamente atualizam e são atualizadas pela memória. Oritual do escrever e/ou o do ler são determinantes do sentido do escrito, porque mobilizam a memória dos sujeitos para validar o documento. $\mathrm{O}$ texto sagrado numa cerimônia religiosa, por exemplo, medeia a interação entre sujeitos, que se afirmam como tais pelo ato religioso. O escrito é referendado pela leitura que atualiza o mito moderador da ordem social.

No eixo denominado Logos, a verdade também funciona como princípio regulador das relações, porém, não como memória. Nesse universo simbólico, o saber não se vincula ao sagrado, trazendo ao senso de verdade a noção do processual, do inédito, da transformação, da instabilidade. A ruptura entre religião, mito e discurso abre diferentes possibilidades de relações sociais, tais como o desenvolvimento da noção de um Estado laico, a diferenciação entre o real e o discursivo, já que a palavra deixa de constituir um dogma, entre outros aspectos. A esfera, nesse paradigma, não é a da expressão, mas a da objetivação, construída com base na distinção entre verdadeiro/falso. O foco recai sobre o objeto. Não há a desconstrução do sujeito, porém há realinhamento do alvo das relações, que não miram o laço social, e sim o rigor conceitual. Grosso modo, em Logos, é a relação com o objeto que agrega a coletividade. 
A escrita tem aí a importante função de tornar objetiva a memória. O registro escrito captura-a fora do sujeito, rearranjando as relações sociais, que podem se dar entre sujeitos e documentos, ainda que tais documentos atualizem vozes subjetivas. $\mathrm{O}$ escrito se institucionaliza e passa a integrar as relações culturais e não apenas a mediá-las.

A ordem social europeia que os portugueses impunham instaurava uma transformação radical, porque esbarrava nas fronteiras de Logos e Mythos. O que Chamie (2002) apresenta como conflito entre cultura letrada vs. cultura de tradição oral pode também ser descrito como redimensionamento das interações válidas. O que de fato poderia integrar o plano não apenas comunicacional, mas principalmente histórico-ideológico, ou seja, o plano de ação e transformação social? Amorim (2009), ao discutir o problema das principais tecnologias da memória - a escrita e a informática - e seus impactos na cultura e na construção dos sujeitos, destaca contrapontos entre a tecnologia da memória na tradição oral e na escrita que permitem analisar a mudança sociopolítica experimentada com o processo de colonização português. A autora pondera:

Nas sociedades de tradição oral, os saberes coletivos se atualizavam no corpo do sujeito singular, fosse pela escrita no corpo, como no caso das pinturas indígenas, fosse pela fala e pelo relato. Os saberes passavam pelo corpo singular, não de modo individual e isolado, mas tornando esse sujeito responsável e participante ativo do manter viva a memória do grupo pela sua incessante transmissão. Do mesmo modo, o destinatário dessa transmissão a acolhia e lhe respondia de corpo inteiro. Estávamos aí em uma situação enunciativa de co-presença. Com a invenção e a democratização da escrita, esta se constitui em uma técnica que traz uma novidade radical: a memória se externaliza e como que sai do corpo do sujeito, da pele ou da voz, para se instalar em algo de fixo e material separado dele - a página escrita e o livro. A técnica mnemônica da escrita transforma o lugar do sujeito no grupo quanto a sua responsabilidade de portador - aquele que recebe, conduz e transmite os saberes coletivos (AMORIM, 2009, p. 15).

Considerando a reconfiguração das relações entre sujeitos a partir da invenção da escrita tal como articulada pela autora, é possível compreender a dimensão metonímica do choque cultural discutido por Chamie (2002). Dois funcionamentos culturais dispõem-se num embate no qual a escrita tem valor institucional em um e não em outro, e a ordem que se impõe valora relações para as quais a escrita opera como poderoso instrumento ideológico.

Nesse cenário, o que se faz com a língua portuguesa no Brasil tem influência em duas dimensões: a das ações sociopolíticas sobre a colônia e a da política inerente ao funcionamento do português na colônia. A partir daí, as possibilidades de construção do senso 
de algo próprio do Brasil é mediado pela língua portuguesa, de maneira que, no processo de construção da brasilidade, não é pertinente cindir política linguística e historicização.

\section{Política de língua e política da língua: \\ a língua portuguesa e seus equipamentos na construção do vernáculo no/do Brasil}

Neste trabalho, a questão da política linguística esbarra em duas dimensões interdependentes. Uma que concerne à ação política na colônia, que inevitavelmente se dá por meio linguístico - aqui referida como política de língua - e outra que diz respeito à natureza necessariamente política do funcionamento de qualquer língua - aqui referida como política da língua. As duas dimensões não se confundem, porém estão necessariamente integradas no processo de historicização e construção vernacular no Brasil.

De acordo com o sociolinguista Louis-Jean Calvet, politica linguística se define pela "determinação das grandes decisões referentes às relações entre as línguas e a sociedade" (CALVET, 2007, p. 11) e se distingue do planejamento linguístico, que consiste da implementação de uma política. Dessa perspectiva, política e planejamento linguísticos dizem respeito às ações de quem tem poder e autoridade para alterar a condição das relações culturais estruturadas pela(s) língua(s). Ainda conforme discute o pesquisador, tais ações sobre a língua podem abordá-la como corpus, ou seja, como forma, ou como status, isto é, como elemento de prestígio social. Considerando o lugar histórico-político assumido pelos portugueses desde o empreendimento da colonização no Brasil, o estudo dessa dimensão envolve rastrear como as decisões e ações dos portugueses orientaram a implementação de sua língua aqui com relevância sociocultural a ponto de alçá-la ao status de língua vernácula. Dito de outra maneira, essa noção de política linguística joga o foco nas ações sobre a colônia, que tornaram a língua portuguesa no Brasil condição culturalmente validada de significar o que é próprio - língua, arte, costume etc. - do Brasil e, assim, constituir um vernáculo. A noção de política de língua localiza a reflexão no plano de ações sobre a língua, seja como política ou planejamento, seja pelo tratamento do corpus ou do status. A política de língua aqui estudada diz respeito ao caráter social imbricado, porém, extrínseco ao funcionamento do português no Brasil no século XVIII.

Todavia, há outra dimensão que também integra a historicização e a construção vernacular, a dimensão política inerente a qualquer língua em uso. No caso, interessa a política da língua portuguesa no Brasil no processo de organização, seja empírica, seja imaginariamente, do português do Brasil. Para acessar essa dimensão política intrínseca, é importante voltar a uma questão primária: o que é língua? 
Voloshinov (1988) advoga que a linguagem desde sua origem, antes mesmo de ser articulada em língua, esteve implicada e imbricada no funcionamento cultural. De acordo com o linguista russo, os primeiros sons a se estabilizarem no processo interacional entre os humanos vinculavam-se às práticas de magia, encantamentos e rituais religiosos. Portanto, não resultaram de expressão individual, mas de atividades que mobilizavam a coletividade. Já desde o primeiro momento, ações culturais e sons fomentaram as condições de produção da linguagem. Aos poucos, esses primeiros sons atrelados às práticas religiosas estabilizam-se a ponto de poderem ser retomados em outras atividades culturais, fazendo ressignificar aquele fragmento de som, por assim dizer. Desse ponto de vista, nunca houve, nem na origem da linguagem, material verbal que prescindisse de acabamento extraverbal. $\mathrm{O}$ autor define:

(...) a língua não é nem uma dádiva de Deus nem da natureza. É o produto da atividade coletiva do homem [sic] e em todos os elementos reflete e refrata a organização tanto econômica quanto sociopolítica da sociedade que a levantou (VOLOSHINOV, 1988, p. 101 - grifos do autor; tradução nossa).

Aí está o caráter inerentemente político da língua. Não há forma verbal articulada que se sustente fora das relações ideologicamente alinhavadas. A política da língua diz respeito a essa interdependência da forma linguística e das condições culturais de significação. No caso do Brasil Colônia, a língua europeia em contexto plurilíngue e bicultural (para situar as tensões ideológicas num embate mais abrangente) não era indiferente à historicização que se atualizava. A política da língua como produto da atividade coletiva aqui desenvolvida não poderia simplesmente reproduzir aquela que se empreendia na metrópole. Pela mesma razão, não poderia o português aqui refletir e refratar a mesma organização econômica e sociopolítica que o português na Europa. A despeito de as duas variedades figurarem uma mesma língua do ponto de vista das especificidades sistêmicas abstratas, era flagrante a diferença entre os pontos de vista que tornavam possível fazer sentido, por meio do português, da organização cultural que se instituía. Assim, a política da língua portuguesa no Brasil Colônia constituiu condição para a elaboração discursiva do português do Brasil.

No encontro dessas duas dimensões da política linguística está localizada a questão do vernáculo. Entendendo que o vernáculo diz respeito à possibilidade de os sujeitos significarem o universo cultural que os reúne como coletividade, a política de língua desenvolvida pela Coroa Portuguesa e a política da língua portuguesa tal como se atualizou nesse cenário figuraram como diretrizes que, por um lado, permitiram a língua assimilar, reacentuar e reorganizar a história e, por outro, permitiram a mesma 
língua ser assimilada, reacentuada e reorganizada no universo cultural que se construía. No Brasil Colônia, havia múltiplas coletividades em contato. Entretanto, o entrelaçamento da política de língua da Coroa e a política da língua portuguesa costurava esses múltiplos agrupamentos em um conjunto que constituiria o Brasil como Império, República, Nação.

Com o avanço do empreendimento português, constituiu-se uma lacuna quanto à mediação da escrita nas relações sociais na Colônia. Quanto mais o funcionamento cultural lusitano se consolidava, maior era a demanda pela documentação escrita. A vinda da família real portuguesa e a transferência da sede da Monarquia para o Brasil em 1808 foram determinantes para o estabelecimento da Impressão Régia, que editaria os documentos oficiais além de um periódico áulico (MARTINS, 2008; MOREL, 2008). Paralelamente, em Londres, nesse mesmo ano, Hipólito da Costa editou um periódico independente, o Correio Braziliense e, assim, a escrita foi penetrando a realidade brasileira.

Aí estão as condições para que a escrita suplante simbolicamente a oralidade no funcionamento cultural e constitua importante equipamento (CALVET, 2007) para política de língua. Como, nesse caso, a língua portuguesa não tinha concorrente com igual recurso - já que o sistema gráfico rascunhado pelos próprios portugueses para as línguas indígenas era incipiente diante daquele do idioma lusitano - o valor cultural da língua da metrópole é gradativamente referendado na Colônia. Para agir nessa nova ordem social era preciso operar esse poderoso equipamento.

Paulatinamente, vão se instalando interações mediadas e/ ou reguladas pela escrita. Afinal, os editos, leis, decretos reais não configuravam registros para serem meramente lidos; antes, alteravam a condição dos sujeitos implicados na Colônia. Diante disso, a política da língua portuguesa no Brasil não poderia deixar de refletir e refratar o valor desse equipamento que atualizava a nova ordem social. Neste ponto, vale citar novamente o linguista russo:

No domínio dos signos, isto é, na esfera ideológica, existem diferenças profundas, pois este domínio é, ao mesmo tempo, o da representação, do símbolo religioso, da fórmula científica e da forma jurídica etc. Cada campo de criatividade ideológica tem seu próprio modo de orientação para a realidade e refrata a realidade à sua própria maneira. Cada campo dispõe de sua própria função no conjunto da vida social (BAKHTIN/ VOLOCHINOV, 1999, p. 33).

O campo de criatividade ideológica liga-se àquelas atividades coletivas que geram a língua, cujos elementos necessariamente refletem e refratam a organização social, política e econômica da coletividade (VOLOSHINOV, 1988, p. 101), mas não coincide com tais atividades. As atividades estão articuladas às relações sociais propriamente ditas, à organização da sociedade e às ações nela autorizadas. O campo diz respeito aos enquadres 
sociais que dão diretrizes para a atualização semiótica. No caso estudado, a atividade de legislar é revestida de sentido pela estabilização do campo da jurisprudência no funcionamento cultural da Colônia. Entretanto, a ordem social - europeia/ocidental - na qual essa legislação efetivamente funcionava ainda se construía no Brasil. Então, como a atualização do campo jurídico influenciou a língua portuguesa e vice-versa?

Semelhantemente, o exercício jornalístico faz sentido a partir do momento em que se reconhece e valida um espaço no qual a forma de saber e de discurso autorizados no jornalismo são referendados pelo funcionamento cultural da Colônia. Magalhães (2011) demonstra como a tensão entre o projeto editorial independente, Correio Braziliense, e o projeto áulico, Gazeta do Rio de Janeiro, lança os fundamentos éticos necessários para a instauração do campo discursivo jornalístico no Brasil. Neste artigo, tomando o campo como premissa, questiona-se: como uma editoria independente pode alterar as políticas linguísticas no Brasil Colônia? Eis as questões a responder.

\section{A lei, o jornal e os discursos que vão tecendo, em português, o vernáculo brasileiro}

Se a língua e as condições sociais, políticas e econômicas são necessariamente integradas, isto é, se a língua não subsiste sem o acabamento ideológico que agrupa sujeitos culturalmente, o português no Brasil terá necessariamente especificidades do Brasil. $\mathrm{O}$ campo da jurisprudência e o do jornalismo no contexto do século XIX, marcas do sucesso colonial português, sinalizam a interpenetração língua/sociedade, de maneira que os documentos que ali circulam atualizam as nuanças linguístico-ideológicas em jogo na Colônia. Nas relações tal como deflagradas por esses campos, a escrita assume condição de equipamento linguístico poderoso, culturalmente relevante para ação e transformação social.

Sendo assim, nesta seção, a análise dos documentos segue o seguinte percurso: 1) descrição do posicionamento dos sujeitos implicados na Carta Régia e no texto editorial a partir das designações daqueles envolvidos na tensão entre povo autóctone e colonizador; 2) avaliação das qualificações atribuídas a esses mesmos sujeitos; 3) demonstração de como os discursos mediados pela língua portuguesa no Brasil e que tornam possível a significação dos fatos históricos representados nos documentos habitam a memória linguístico-cultural do português do Brasil.

A Carta Régia (doravante, CR), assinada pelo Príncipe Regente, D. João VI, e endereçada ao Governador e Capitão General da Capitania de Minas Gerais, Pedro Maria Xavier de Ataide e Mello, dá providências sobre a guerra contra povos autóctones do Brasil que não aceitavam as coerções sociopolíticas, econômicas e culturais de Portugal. Ao todo, são seis ordenanças referentes 
à organização militar e administrativa dos representantes da metrópole com vistas à "redução", "pacificação", "civilização" dos índios (BRASIL, 1808). Do ponto de vista empírico, a trama dialogal do documento tem o Príncipe Regente como aquele que fala, o Governador como destinatário, e, como assunto, as dificuldades para o desenvolvimento do projeto colonizador impostas, em parte, pela resistência de algumas tribos indígenas e, em parte, pelos gastos com pessoal na estrutura militar e burocrática organizada pela própria Coroa. Discursivamente, há um diálogo entre sujeitos comprometidos com o funcionamento cultural lusitano. A população autóctone e os representantes do empreendimento português no Brasil aparecem como objeto do diálogo. No seguinte quadro, agrupam-se as designações referentes, de um lado, ao colonizador e, de outro, ao povo autóctone:

Quadro 1: Designações e suas reformulações de colonizador e de povo autóctone

\begin{tabular}{|c|c|}
\hline COLONIZADOR & Autóctone \\
\hline $\begin{array}{l}\text { - Governador e Capitão General da } \\
\text { Capitania de Minas Gerais } \\
\text { - Proprietários [de fazendas], } \\
\text { - Portuguezes } \\
\text { - Soldados Infantes } \\
\text { - Officiaes affectivos } \\
\text { - Comandantes [de terrenos, de Pri- } \\
\text { meira, de Segunda etc. Divisão } \\
\text { - Soldados } \\
\text { - Coronel do Regimento de linha } \\
\text { - Coronel Inspector dos destacamen- } \\
\text { tos da Capitania } \\
\text { - Tenente Coronel } \\
\text { - Major } \\
\text { - Ouvidor de Comarca na qualidade } \\
\text { de Auditor do Regimento } \\
\text { - Escrivão Deputado da Junta da } \\
\text { Fazenda } \\
\text { - Alferes } \\
\text { - Capitão Mór Regente da Campanha } \\
\text { - Thesoureiro da Intendencia de Villa } \\
\text { Rica } \\
\text { - Fieis de Registro } \\
\text { - } 7 \text { nomes próprios (incluindo o do } \\
\text { destinatário) }\end{array}$ & $\begin{array}{l}\text { - Indios Botocudos, } \\
\text { - Indios Botecudos, } \\
\text { - Indios atropophagos, } \\
\text { - Vassalos uteis, } \\
\text { - Variedades de Indios, } \\
\text { - Indios domesticos, } \\
\text { - Raça antropophaga, } \\
\text { - Prisioneiro de guerra } \\
\text { - Indios bravos } \\
\text { - Outras raças de Indios } \\
\text { - Indios }\end{array}$ \\
\hline
\end{tabular}


Nas referências aos representantes do projeto colonizador, predominam as designações de postos militares ou da administração pública, seguido de nomes próprios. Aí há total consonância entre o nome e a língua que atualiza a designação. O mesmo já não ocorre com as referências aos autóctones. Nota-se, por exemplo, que a designação vassalos uteis não significa, senão na ordem social europeia. Assim, fica evidente que há um olhar sobre o referido, um juízo, um valor que estrutura o documento. Dizer que a CR redigida por um monarca é escrita do ponto de vista do colonizador seria, no mínimo, tautológico. Entretanto, não é óbvio dizer que a perspectiva marcada na língua acrescenta a essa mesma língua valores que traduzem a ordem social, política e econômica da Colônia. Como isso se dá?

Dentre diferentes possibilidades de acesso à orientação ideológica estruturante da CR, destaca-se o então neologismo cunhado para designar os índios que resistem à aculturação portuguesa: botocudos, com a variante botecudos. Morfologicamente, não há nenhuma novidade. Do substantivo botoque ou batoque - vocábulo de origem incerta, possivelmente do gascão bartoc, designa um orifício largo na parte superior de pipas, tonéis, barris etc., por onde se introduz líquido; designa também rolha ou pedaço de madeira com que se veda tal orifício (CUNHA, 2010) - forma-se, por derivação própria, a partir do acréscimo do sufixo -udo - do latim, ùtu, que exprime qualidade em abundância (COUTINHO, 2005, p. 171) - o nome botocudo. Semanticamente, identifica-se uma apreciação valorativa na formação do vocábulo. A noção de abundância convocada pelo sufixo geralmente é traduzida pela ideia de exagero na palavra derivada, como se vê em barrigudo, carrancudo, bigodudo etc. Não é diferente neste caso: botocudo encerra uma orientação negativa, marcando no item lexical o estranhamento daquilo que é nomeado. Discursivamente, a designação se dá pela metonímia, ratificando uma abordagem estereotipada e tendenciosa. $\mathrm{O}$ adereço, o enfeite é tomado pelo todo de um povo, em sua dimensão étnica, política, simbólica, e o ato de designá-lo assim impinge ao léxico da língua portuguesa não apenas um item, mas um índice da memória desse valor. Componentes das designações dos autóctones, as qualificações bravos, antropophagos em direta oposição a mansos, domésticos reforçam a postura de repulsão àqueles que não se acomodavam à ordem imposta pela Coroa. Botocudo, na condição de designação de um povo, simultaneamente reflete as condições sociais de um momento do Brasil Colônia e refrata o que é fato histórico, localizado no mundo biossocial, como valor pejorativamente significado na língua, significante na cultura. Aí está um flagrante vernacular no e do Brasil.

Em outro campo discursivo, a circulação do vocábulo corrobora a formação própria do Brasil, mas modifica-a com a instalação do embate de ideias. O texto editorial do Correio Braziliense, jornal 
independente (portanto não compelido a reproduzir os valores da Coroa) editado em Londres por Hipólito da Costa, encontra-se numa seção de natureza editorial (não noticiosa) intitulada Miscellanea. Como o próprio termo sugere, trata-se de uma editoria que reúne diferentes assuntos. Na edição de outubro de 1808, quinta edição do jornal, um desses textos editoriais intitulado Brazil constitui espaço de crítica à Coroa Portuguesa.

$\mathrm{Na}$ abertura do texto, há atestação de recebimento de documentos que tratam dos assuntos ali discutidos, o que é fundamental para o campo jornalístico. Uma vez assegurada a pertinência e a relevância da palavra editorial para o campo da criatividade ideológica em que se inscreve, segue uma severa crítica a valores do projeto colonizador. Eis o fragmento:

Entre os Documentos recebidos, se acha uma Declaração de Guerra da Corte do Brazil contra os índios Botecudos. Ha muitos tempos que naõ leio um papel taõ celebre; e o publicarei quando receber a resposta que S. Excellencia o Secretario de Estado dos Negócios Estrangeiros e da Guerra da NaçaÕ dos Botecudos, dér a esta grande peça de Diplomacia; porque he natural que este longo papel que contem 8 paginas, seja dirigido aquella Naçaõ: he verdade que ella inda nao sabe lêr, mas aprenderá, julgo eu, para responder a isto.

Há inúmeras marcas da dissonância entre este texto e a CR. Mas, para seguir o paralelismo analítico, observem-se apenas as designações.

Quadro 2: Designações em outro campo

\begin{tabular}{|c|c|}
\hline COLONIZADOR & Autóctone \\
\hline -Corte do Brazil & $\begin{array}{l}\text { - Indios Botecudos; } \\
\text { - S. Excellencia o Secretario de } \\
\text { Estado dos Negócios Estrangei- } \\
\text { ros e da Guerra da Naçaõ dos } \\
\text { Botecudos (grifo nosso); } \\
\text { - Nação }\end{array}$ \\
\hline
\end{tabular}

Fonte: BRAZIL, 1808, p. 421.

Como este é apenas um fragmento do texto, não é possível proceder à comparação quantitativa de termos designativos. Do ponto de vista qualitativo, porém, há importantes aspectos a serem destacados. A referência à Coroa não traz nenhuma refração relevante, exceto pela explicitação do caráter tanto toponímico quanto genitivo: Corte do Brazil. De qualquer modo, preservam-se os parâmetros linguístico-culturais europeus para fazer sentido da figura do colonizador aqui.

A designação dos autóctones, no entanto, não segue o mesmo referencial. Tomada de um texto de outro campo, botecudo [variante de botocudo] guarda os estratos morfossemânticos do neologismo 
(reflexão das condições de produção do vocábulo), porém refrata outros valores. A despeito da manutenção morfológica, o vocábulo no âmbito da palavra editorial não significa os autóctones com estranhamento. Diferentemente, a mobilização de um conceito próprio da ordem social que se consolidava na Europa - nação para compor a designação do povo autóctone articula de outra maneira o estranhamento.

A ideia de nação não era antiga. Remontava ao século anterior e tinha a Europa como nascedouro (THIESSE, 1999). Se o vocábulo e o ideal são familiares, respectivamente, à língua portuguesa e a seu ambiente de origem, a designação do autóctone por ele não o é. Na palavra editorial encontram-se dois juízos: 1) aquele que adere à ordem europeia e convoca seu universo de sentido e 2) aquele que o altera, fazendo o sentido próprio do universo simbólico do Brasil Colônia. Não só pelo código linguístico escolhido para significar esses dois juízos - a língua portuguesa -, mas também pelos discursos e ideais convocados, somente o lusitano poderia acessar os efeitos de sentido provocados pelo texto jornalístico. Quem toma a palavra no texto editorial posiciona-se política e discursivamente contrário à Coroa, mas com ela parece alinhar-se culturalmente. A ironia estabelecida pela menção a um cargo fictício - S. Excellencia o Secretario de Estado dos Negócios Estrangeiros e da Guerra da Naçaõ dos Botecudos - só se sustenta de um ponto de vista que articule os dois juízos. Assim, flagra-se um índice vernacular brasileiro que encerra a contradição como condição de produção.

Ambos os textos - a CR e o editorial - apresentam pontos e contrapontos. Por um lado, os dois referendam o escrito como instituição, de maneira que, nesse plano cultural, é possível afirmar que a "CR diz X" ou o "jornal critica Y". Os dois operam a partir do referencial Logos e mobilizam campos discursivos que consolidam valores europeus em detrimento de uma ordem social outra, na qual não se prevê a escrita como equipamento linguístico, como instrumento ideológico. Nesse ponto, tanto um quanto outro corroboram a política de língua a favor de um Brasil lusofônico. Afinal, o processo de significação em jogo entre esses documentos mostra como a manutenção da hegemonia e a resistência a ela são, em última instância, legitimadoras da ação a favor da língua europeia no Brasil. Por outro lado, o acabamento vernacular preserva também contrapontos.

Se a CR configurou uma interação restrita entre Príncipe Regente e Governador e Capitão General da Capitania de Minas Gerais, os desdobramentos culturais do documento vão além daquilo recuperado na trama dialogal. A palavra escrita com força de lei imprime na língua um tom valorativo que passa a habitar o léxico. Com o neologismo, a língua portuguesa no Brasil registra em sua memória a apreciação do colonizador acerca dos 
autóctones resistentes ao empreendimento europeu. Em contrapartida, a palavra escrita jornalística mobiliza também o reverso. A repulsa não se orienta para o autóctone exótico, mas para o projeto colonizador e a assimetria sociocultural que promove. Assim, a política da língua se constrói pela tensão de olhares, de perspectivas, de modos de significar, tecendo nuanças próprias do português do Brasil.

A fim de demonstrar o alcance dessa tensão na construção vernacular brasileira, apresenta-se, no quadro abaixo, o verbete botocudo em três dicionários contemporâneos da língua portuguesa em sua versão digital. Dois brasileiros e um português. A justaposição dos olhares evidencia fronteiras vernaculares entre uma e outra variante da língua.

\section{Quadro 3: Uma língua; dois vernáculos}

\begin{tabular}{|c|c|c|}
\hline Aulete & HouAISS & PORTO \\
\hline $\begin{array}{l}\text { (bo.to.cu.do) sm. } \\
\text { 1. Etnol. Indígena de } \\
\text { qualquer tribo que } \\
\text { tivesse por tradição } \\
\text { o uso de botoque } \\
\text { no lábio inferior } \\
\text { [Designação dada } \\
\text { pelos portugueses.] } \\
\text { 2. Gloss. Família } \\
\text { linguística de línguas } \\
\text { indígenas, do tronco } \\
\text { macro-jê } \\
\text { 3. Pej. Pessoa } \\
\text { de hábitos e } \\
\text { comportamento } \\
\text { rudes, toscos } \\
\text { 4. Pej. Habitante da } \\
\text { roça; CAIPIRA } \\
\text { 5. Do ou ref. ao } \\
\text { botocudo (1, 2) } \\
\text { 6. Incivilizado, inculto } \\
\text { 7. Caipira } \\
\text { [F.: botoque + -udo.] }\end{array}$ & $\begin{array}{l}\text { Datação c1764 cf. CSHis } \\
\text { Acepções } \\
\text { a substantivo masculino } \\
\text { 1 Rubrica: etnologia. denominação } \\
\text { dada pelos portugueses a indígena } \\
\text { pertencente a grupos de diversas } \\
\text { filiações lingüísticas e regiões } \\
\text { geográficas por usarem botoques } \\
\text { labiais e auriculares; eram assim } \\
\text { chamados os caingangues e os } \\
\text { xoclengues de Santa Catarina, os } \\
\text { bacuéns, os cracmuns, [...] } \\
\text { Obs.: etnm.br.: Botocudo } \\
2 \text { Rubrica: lingüística. família } \\
\text { lingüística do tronco macro-jê } \\
\text { adjetivo } \\
3 \text { relativo a botocudo (acp. } 1 \text { e 2) ou } \\
\text { aos botocudos ('grupos indígenas') } \\
\text { adjetivo e substantivo masculino } \\
\text { Uso: pejorativo. } \\
4 \text { que ou quem é inimigo das boas } \\
\text { maneiras; rude, incivil } \\
5 \text { que ou quem mora na roça; caipira } \\
\text { Etimologia } \\
\text { botoque + -udo, com valor desde } \\
\text { sempre pejorativo, por 'bárbaro, } \\
\text { rude, selvagem' } \\
\text { Sinônimos } \\
\text { como adj.s.m.: ver sinonímia de } \\
\text { caipira } \\
\text { Antônimos } \\
\text { como adj.s.m.: ver antonímia de } \\
\text { caipira }\end{array}$ & $\varnothing$ \\
\hline
\end{tabular}

A análise das variações dos verbetes (ou da ausência dele) extrapolaria os objetivos deste artigo. As entradas são apresentadas apenas como flagrantes da memória discursivo-cultural da palavra que sinaliza fronteiras na língua e atualiza marcas vernaculares na contemporaneidade. 


\section{Considerações finais}

Neste artigo, propôs-se discutir a questão vernacular brasileira, notadamente marcada pela colonização lusitana, porém não limitada ao ponto de vista europeu. Significar a história do Brasil demanda o rastreamento dos sentidos produzidos pelas e para as ações políticas e as respostas por elas convocadas desde o projeto que empreendeu neste espaço a unidade de uma colônia. A partir daí, dar sentido ao que é próprio da cultura construída aqui fica marcado pela tensão entre a estabilidade da identidade coletiva que agrupa uma multiplicidade étnica, linguística, religiosa etc. e a instabilidade da alteridade de significar essa coletividade pela língua portuguesa. Assim, tratar do vernáculo do Brasil implica lidar com diferentes apreciações valorativas, atualizadas pela política de e da língua.

Para tanto, buscou-se resgatar a memória que vivifica a língua, voltando o olhar para o nascedouro não apenas de formas e estruturas, mas principalmente para o sentido e o valor que inevitavelmente revestem essas formas e estruturas nos diferentes contextos. Dessa maneira, este estudo traz contribuições em duas instâncias.

A primeira diz respeito ao desafio metodológico de tratar da dimensão política tanto extrínseca quanto intrínseca do vernáculo e estabelecer relações pertinentes entre dois textos de campos diferentes sem, todavia, limitar-se às retomadas de um pelo outro. Espera-se ter demonstrado que a tarefa de significar o Brasil se dá na interseção do olhar europeu e o do não europeu e que a língua portuguesa não está imune a isso.

A segunda refere-se ao tratamento da escrita como fenômeno histórico e cultural do Ocidente atualizado nas condições em que se torna equipamento linguístico de poderoso calibre ideológico na historicização do Brasil. Mais do que seu caráter documental, recupera-se sua função como instrumento de transformação cultural que definiu possibilidades vernaculares. Uma vez revestida de valor simbólico na ordem social que se instituía, a escrita passa a regular modos de agir na sociedade. Diante disso, é pertinente afirmar que o vernáculo do Brasil se escreve no encontro dos pontos e contrapontos de perspectivas, e é assim que a língua portuguesa no Brasil traceja as nuanças do Brasil.

\footnotetext{
Abstract

Traditionally the history of Brazil is told from the European point of view, more specifically, from the Portuguese perspective, and the linguistic issue plays an important role in the way 'Brazility' could and can be signified. The aim in this article is to demonstrate how writing establishes an arena of meanings determinant to discourses
} 
constitutive of the sense of vernacular in and of Brazil. To achieve this objective, two documents flagrant of the tension established by the linguistic policy of the Portuguese Crown were selected: a) a Royal Letter declaring war against the so called Botocudo Indians, and $b$ ) an editorial text published in Correio Braziliense about that Letter. The analysis of these documents outlines two fundamental points to the possibility of construction of the vernacular: 1) the Portuguese linguistic policy imposed a literate order and the knowledge authenticated by and through that order in detriment of an oral-driven order and the knowledge it valued; 2) writing corroborated at one time the value and the reaccentuation of the value of the Portuguese language in the cultural functioning which was instituted, constituting instrument of confirmation and questioning of linguistic ideologies. Therefore, writing in Brazil mobilised discursive fields regulator of the relation between language and society decisive for the historicisation of the country.

Keywords: language policies; Portuguese language; vernacular; writing.

\section{REFERÊNCIAS}

AMORIM, M. Raconter, démontrer, ... survivre: formes de savoirs et de discourse dans la culture contemporaine. Ramonville SaintAgne: Éditions Èrès, 2007.

. Memória do objeto - uma transposição bakhtiniana e algumas questões para a educação. Bakhtiniana: Revista de Estudos do Discurso, São Paulo, v. 1, n. 1, p. 8-22, $1^{\circ}$ sem. 2009.

AULETE, C. Dicionário da Lingua Portuguesa. Disponível em: http:// aulete.uol. com.br/site.php?mdl=aulete_digital\&op=loadVerbete\&pesquisa $=1 \&$ palavra=botocudo\& $\mathrm{x}=9 \& \mathrm{y}=7$. Acesso em: $2 \mathrm{dez}$. 2011.

BAKHTIN, M. M./ VOLOCHINOV, V. N. Marxismo e Filosofia da Linguagem. Problemas fundamentais do método sociológico na Ciência da Linguagem. Tradução de Michel Lahud e Yara Frateschi Vieira. 9. ed. São Paulo: Hucitec, 1999.

BRASIL. Carta Régia, de 13 de maio de 1808. Manda fazer guerra aos indios Botocudos. BRASIL. Leis etc. Colecção das Leis do Brazil de 1808. Rio de Janeiro: Imprensa Nacional, 1891, p. 37-41. Disponível em: http://www.planalto.gov.br/ ccivil_03/revista/Rev_18/CartaRegia_1305.htm. Acesso em: 30 nov. 2011. 
BRAZIL. Correio Braziliense. Vol. I, Londres: W. Lewis, Paternoster. Row, out. 1808. Miscellanea, p. 420-425. Disponível em: http:// www.brasiliana.usp.br/bbd/handle/1918/060000-005\#page/1/ mode/1up. Acesso em: 17 set. 2010.

CALVET, L-J. As políticas linguísticas. Tradução Isabel de Oliveira Duarte, Jonas Tenfen, Marcos Bagno. São Paulo: Parábola Editorial/IPOL, 2007.

CHAMIE, M. Caminhos da Carta. Ribeirão Preto: FUNPEC-RP, 2002. COUTINHO, I. de L. Gramática Histórica, $7^{\mathrm{a}}$ ed.. Rio de Janeiro: Ao Livro Técnico, 2005.

CUNHA, A. G. da. Dicionário etimológico da língua portuguesa. 4. ed. Rio de Janeiro: Lexikon, 2010.

DEL PRIORE, M.; VENANCIO, R. Uma breve história do Brasil. São Paulo: Editora Planeta do Brasil, 2010.

HOUAISS, A. Dicionário Houaiss da Lingua Portuguesa. Disponível em: http://houaiss.uol.com.br/busca.jhtm?verbete=BOTOCUDO\&stype=k. Acesso em: 2 dez. 2011.

MAGALHÃES, A. S. Fundamentos éticos da esfera discursiva da imprensa no Brasil: um jogo de epígrafes e memórias. Trabalhos em Linguística Aplicada, Campinas, v. 50, n. 1, p. 27-43, jan./jun. 2011.

MARIANI, B. Colonização linguística. Línguas, política e religião no Brasil (séculos XVI a XVIII) e nos Estados Unidos da América (século XVIII). Campinas: Pontes, 2004.

MARTINS, A. L. Imprensa em tempos de Império. In: MARTINS, A. L.; LUCA, T. G. (org.) História da imprensa no Brasil. São Paulo: Contexto, 2008.

MOREL, M. Os primeiros passos da palavra impressa. In: MARTINS, A. L.; LUCA, T. G. (org.) História da imprensa no Brasil. São Paulo: Contexto, 2008.

NARO, A. J.; SCHERRE, M. M. P. (orgs.) Origens do português brasileiro. São Paulo: Parábola Editoria, 2007.

NOLL, V. O Brasil Colônia entre a língua geral e o português. In: NOLL, V.; DIETRICH, W. (ors.) O português e o tupi no Brasil. São Paulo: Contexto, 2010.

PORTO EDITORA. Dicionário da Lingua Portuguesa. Disponível em: http://www.infopedia.pt/lingua-portuguesa/botecudo . Acesso em: 2 dez. 2011.

THIESSE. A-M. La création des identités nationales. Europe XVIIIe - XXe siècle. Paris: Editions du Seuil, 1999.

VOLOSHINOV, V. N. [M. M. BAKHTIN]. What is language? In: SHUKMAN, A. (org) Bakhtin school papers. Russian Poetics in Translation. Somerton: Old School House, 1988. 